\title{
Model Research on In-Service Learning of Intellectualization of Aerospace Knowledge
}

\author{
Haoli Ren $\left(D,{ }^{1}\right.$ Hailan $\mathrm{Li}^{2}$, and Kongyang Peng ${ }^{2}$ \\ ${ }^{1}$ Space Engineering University Space Security Research Center, Beijing, China \\ ${ }^{2}$ Space Engineering University Sergeant School, Beijing, China \\ Correspondence should be addressed to Haoli Ren; rholy@sina.com
}

Received 13 September 2021; Revised 15 November 2021; Accepted 26 November 2021; Published 18 December 2021

Academic Editor: Fazlullah Khan

Copyright (c) 2021 Haoli Ren et al. This is an open access article distributed under the Creative Commons Attribution License, which permits unrestricted use, distribution, and reproduction in any medium, provided the original work is properly cited.

With the development of vocational education, it is necessary to construct the pattern of lifelong learning. To push delivery learning resources and provide a learning environment, it is necessary to innovate in-service learning mode. According to the characteristics of the aerospace position, the capacity model was studied and proposed. Based on the ability model, the intelligent in-service learning model is studied and proposed to improve the precision service quality. From the angle of principle and learning process, this paper discusses the intelligent in-service learning mode of including the learning model based on knowledge map and the learning model based on seminar hall. The framework of the job knowledge map is constructed according to the post ability model which is based on professional knowledge, professional skills, and professional quality. The intelligent on-the-job learning model includes four elements: (i) learning platform, (ii) learning resources, (iii) learning methods, and (iv) learning evaluation. The learning portrait can record and visualize the information of learning, including content, activities, and effects.

\section{Introduction}

With the further development of vocational education, large-scale cultivation of high-quality and professional newtype talents has become an inevitable trend. Vocational education should pay close to missions and tasks, position duty performance, and career development, construct the pattern of learning for whenever and wherever, even lifelong, and improve the network, open and full coverage of vocational education system [1].

At present, the vocational education teaching form is dominated by web-based curriculum, and the state has invested and constructed a batch of high-quality MOOC platforms [2]. The shift to online and blended teaching and learning provides new opportunities for content delivery, interaction, and facilitation of learning. The success of online or blended learning delivery is, to a large extent, dependent on the knowledge, expertise, support, and leadership available in the transition to this new way of learning. In addition, quality teaching is a long-standing challenge in higher education where faculty are not certified to teach. In order to use online and blended learning but maintain or enhance quality teaching, more work to identify, disseminate, and implement best practices is required.

Users can make on-post learning with the help of MOOC platform, but these have no platform aiming at aerospace positions. Based on the existing platforms, this study proposes an intelligent on-the-job learning model for knowledge learning and training of aerospace positions. Intelligent onthe-job learning mode emphasizes autonomous learning and knowledge sharing and provides accurate service for aerospace post learning through intelligent technical means [3].

Following are the main innovations points of this paper:

(1) This paper proposes the characteristics of aerospace posts. The post competency model framework represents the ability requirements based on the primary level, intermediate level, and advanced level. Three 
ability items are designed, namely, "professional knowledge," "professional skills," and "professional quality."

(2) This paper proposed the intelligent on-the-job learning model as a kind of learning model that includes four elements: (i) learning platform, (ii) learning resources, (iii) learning methods, and (iv) learning evaluation.

(3) The learning process is based on a knowledge map where the learning content is selected to meet the needs of work. The knowledge map consists of five steps including (i) building a post ability model, (ii) forming a knowledge map, (iii) selecting knowledge points for learning, (iv) training, and (v) learning portrait.

(4) The logical basis of learning style based on seminar hall is explained, in which users (learners and sharers) communicate and share knowledge.

The structure of this paper is organized as follows. In Section 2, the aerospace post capacity model framework is discussed. In Section 3, the learning methods are explained in which learning style based on the knowledge map and seminar hall is discussed. The whole paper is concluded in Section 4. In Section 5, the future work is discussed.

\section{Related Work}

2.1. A Model Framework of Aerospace Post Capacity. According to the characteristics of aerospace posts, the post competency model framework is divided into two dimensions: vertical ability level and horizontal ability elements [4]. In terms of ability level, three levels, from low to high, are designed to represent the ability requirements of different positions and cultivate professional talents at different levels. (i) The primary level is to have the basic knowledge of the post and be able to operate it simply. (ii) The intermediate level is to master the in-depth theoretical knowledge of the post and be able to learn and apply it. (iii) The advanced level is to master the theoretical knowledge and cutting-edge technology of the post and to be able to integrate. In terms of ability composition, three ability items are designed, namely, "professional knowledge," "professional skills," and "professional quality" [5-7]. (i) Professional knowledge refers to the domain-specific knowledge of the post, including the basic theory and advanced technology. (ii) Professional skill refers to the experience knowledge, operation skill, and so on. (iii) For professional quality, a very important trait is the ability to handle stressful situations, working to the same standards regardless of urgency. Space literacy refers to the basic knowledge related to the professional field of the post, including science, culture, art, and other knowledge. The model framework of aerospace post capability is shown in Figure 1.

The model framework of aerospace post capability is the cornerstone of the intelligent on-the-job learning model. The core of the model is to provide users with a job knowledge map and knowledge sharing environment, and

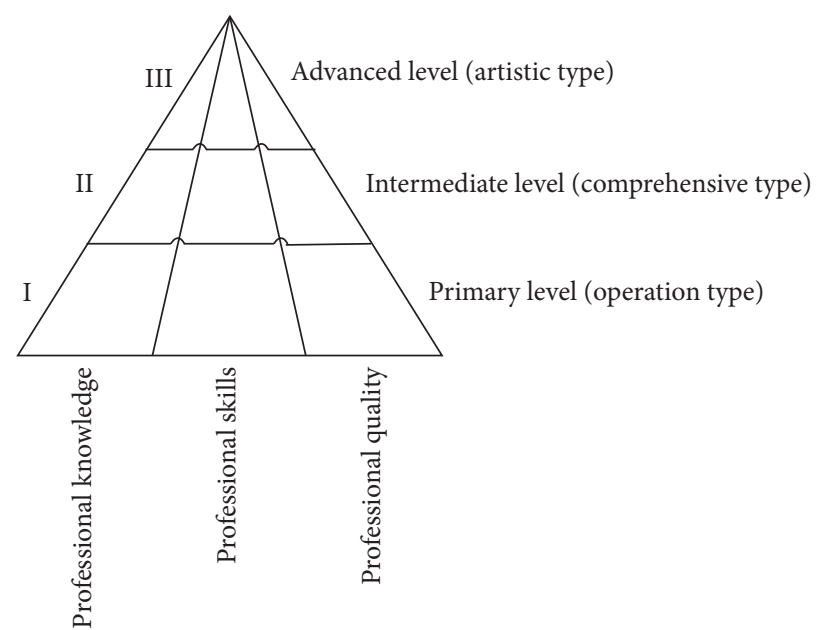

FIgure 1: The post capability model.

the framework of the job knowledge map is constructed according to the post ability model.

2.2. The Pattern of Intelligent On-Post Learning. Learning pattern is a relatively stable structure framework of learning activity designed to achieve specific learning objectives under the guidance of certain teaching ideologies and study theory, as well as specific and operable learning practice procedures and methods.

Under the guidance of the theory of Internet + autonomous learning + cooperative learning, the intelligent onthe-job learning mode is a kind of learning model that aims at learning and sharing knowledge to realize the rapid improvement of post competency. The traditional learning model includes teaching activities, teaching materials, learning activities, teaching evaluation, and so on. The intelligent on-the-job learning model includes four elements: (i) learning platform, (ii) learning resources, (iii) learning methods, and (iv) learning evaluation.

(i) Learning platform: the learning platform works on the intelligent terminal, which can provide users with abundant learning resources and convenient learning tools and establish a learning environment that can be learned at any time.

(ii) Learning resource: the presentation form of learning resources has changed the past practice of dividing knowledge points according to chapters. According to the model of aerospace post capacity, we make full use of big data technology and knowledge map technology. Through backstage collection and excavation, the regulation between post capacity demand and post knowledge, and then artificial intelligence algorithm screening, the position knowledge map is formed. Each knowledge point in the job knowledge map is generated by big data technology, which is the front edge and focus of the position. Each knowledge point is relatively independent complete knowledge, and there is a 
logical connection between them, which is a complete knowledge system.

(iii) Learning method: the learning style based on the seminar hall refers to the learning method that users discuss, exchange, or share knowledge with other users based on individual autonomous learning with the help of the communication tool of the seminar hall.

Learning styles are divided into knowledge mapbased learning and seminar-based learning. The learning style based on the knowledge map is that users generate the knowledge map through intelligent terminals and make full use of fragmented time to learn independently. At the same time, the self-control of learning portraits that feedback through the platform emphasizes the dominant position of learners.

(iv) Learning evaluation: it refers to learning portraits, which visualize the learning activities and effects through the user learning behavior data of platform statistics.

The logical basis of the intelligent on-the-job learning model is to stimulate the enthusiasm of users for learning, to learn actively and autonomously. To achieve this goal, it is necessary to deeply understand the learning needs of users. With the promulgation and implementation of the new regulations, job rotation will be more frequent, and the requirements for professional knowledge become higher and higher. The learning needs of users mainly have four aspects: learning needs generated by job qualification, job mobility, performance evaluation, and job promotion [8]. From the perspective of learning needs, an intelligent on-the-job learning model is designed, and the logic diagram is shown in Figure 2.

Through the change of learning mode, we hope to improve the pertinence of on-the-job learning content, to improve the enthusiasm of learning and the initiative of sharing knowledge. It enables users to quickly be competent for a post need in terms of knowledge reserves.

\section{Learning Method}

3.1. Learning Style Based on the Knowledge Map. The logical basis of the learning method based on the knowledge map is "practice to learn," and the corresponding learning content is selected to meet the needs of work. Compared with academic education, vocational education pays more attention to fast-competing job tasks in the position, focusing on vocational skills rather than the improvement of simple subject knowledge [9]. The learning content of users should be the knowledge, skills, and accomplishments directly related to the positions.

The learning process based on a knowledge map includes the following five steps: (i) building a post ability model, (ii) forming a knowledge map, (iii) selecting knowledge points for learning, (iv) training, and (v) learning portrait. The learning process based on the knowledge map is shown in Figure 3.
The learning process based on the knowledge map is as follows:

(i) Post capacity model: build the post competency model according to the post needs and framework, proposed in Sections 2 and 3.

(ii) Clarifying the learning objectives: users select the positions to be studied and the level of learning after clarifying the learning objectives.

(iii) Knowledge map: after confirmation, the system will automatically generate knowledge maps based on the post capability model.

(iv) Selecting knowledge points for learning: users can randomly select knowledge points in the knowledge map for autonomous learning.

(v) Training project: after accomplishing a knowledge point, the system will give the training project, and the user will complete the learning tasks according to it.

(vi) Learning portrait: the user's learning content, process, and the outcome will be recorded by the system. Also, the portrait of the learning behavior will be given.

A knowledge map is given in the form of a mind map, as shown in Figure 4.

3.2. Learning Styles Based on Seminar Hall. The logical basis of learning style based on seminar hall is knowledge sharing. The "knowledge" here comes not only from textbooks but also from personal practice [10]. The core of the learning method based on the seminar hall is to create the seminar hall, in which users (learners and sharers) communicate and share knowledge (as shown in Figure 5).

The learning process based on seminar hall is as follows:

(i) Users raise questions in the seminar hall.

(ii) After other users see the questions, they answer (may not be unique) the questions according to their understanding. The seminar hall will give the answers of different users in order.

(iii) Other interested users can discuss and follow up the post, and the posts are also given in the seminar as answers.

(iv) Users who ask questions independently choose answers in the seminar hall.

(v) The system, according to the quality and score of answers and posts of each user involved in the discussion, gives the users who have high scores the title of web celebrities of knowledge.

(vi) The seminar hall occasionally recommends popular knowledge according to current affairs for users to learn and discuss.

The social function is emphasized based on the learning mode of the seminar hall. Users can fully discuss, share knowledge, and exchange information in the seminar hall, and those with more contribution of knowledge, ideology, and activity can become web celebrities of knowledge. 


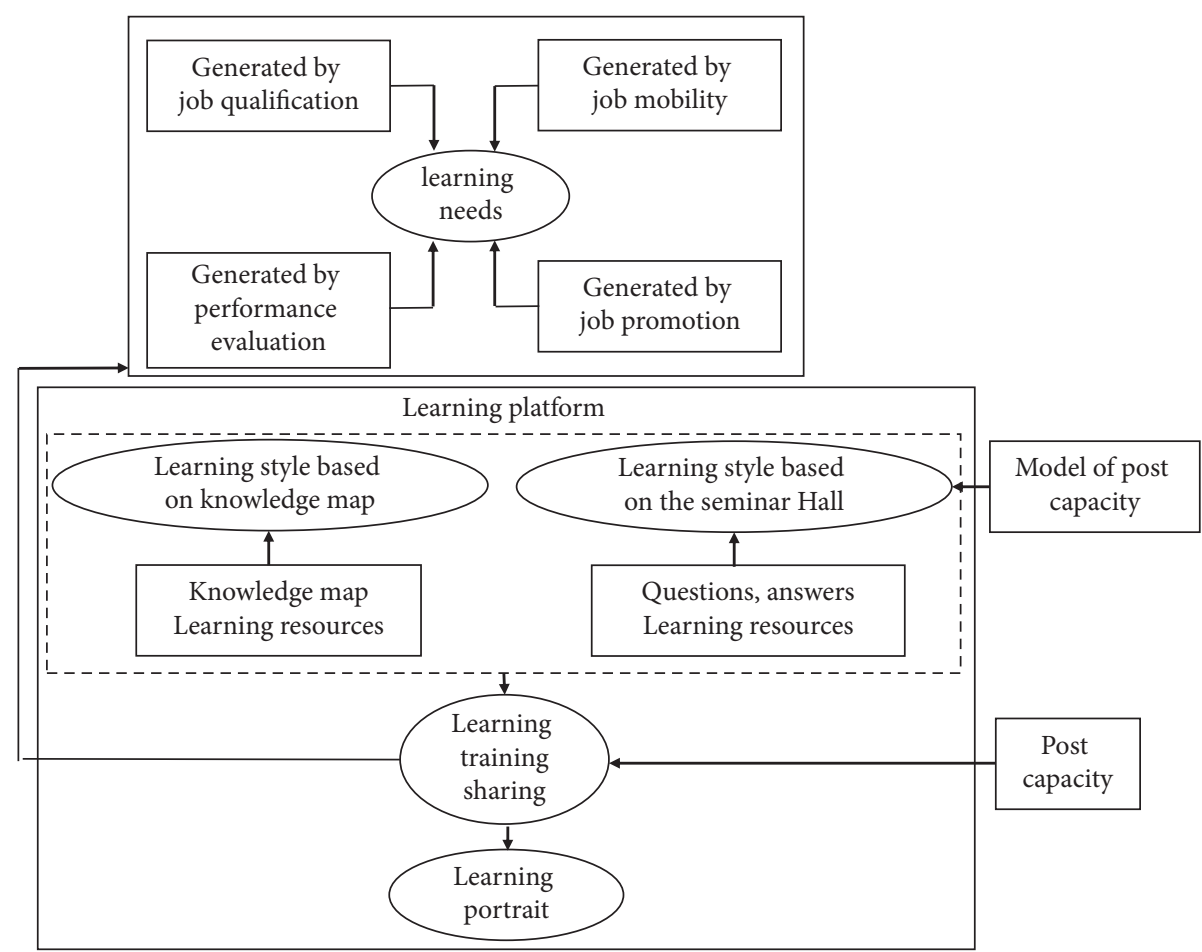

FIgURE 2: Logic diagram of intelligent on-the-job learning mode.

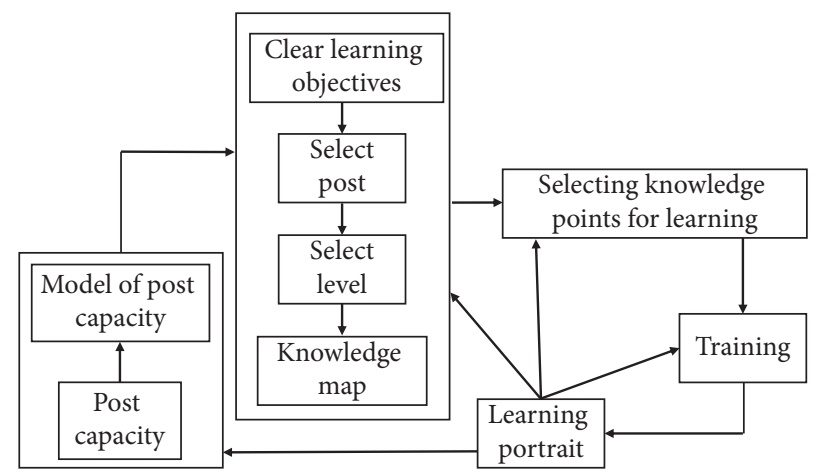

FIGURE 3: Learning process-based knowledge map.

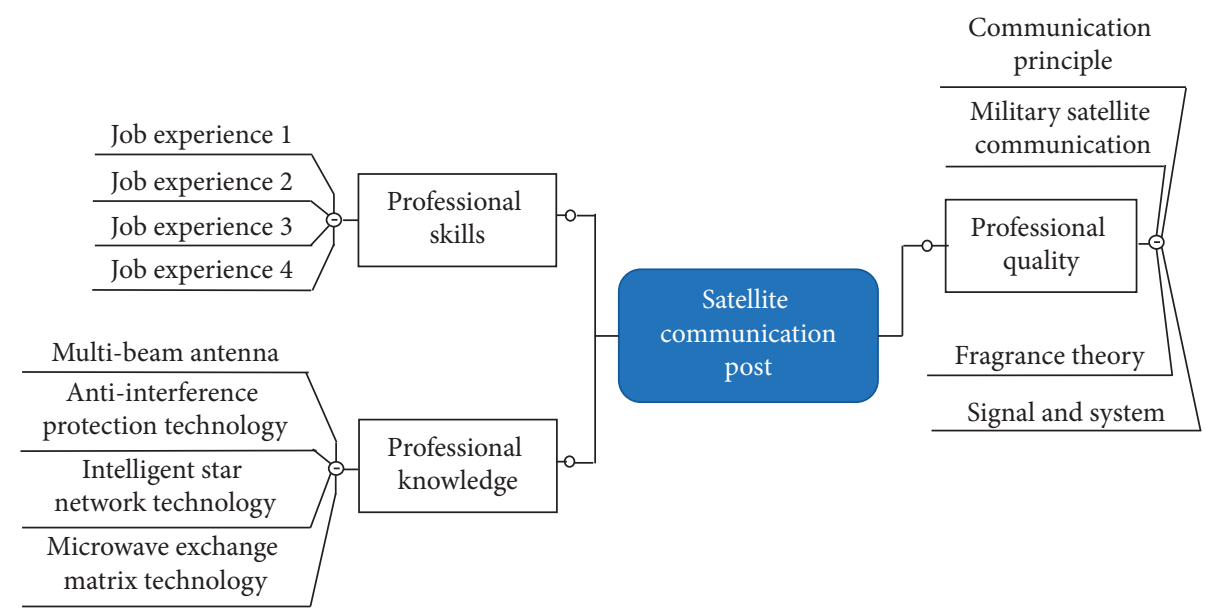

FIgURE 4: The schematic diagram of the knowledge map. 


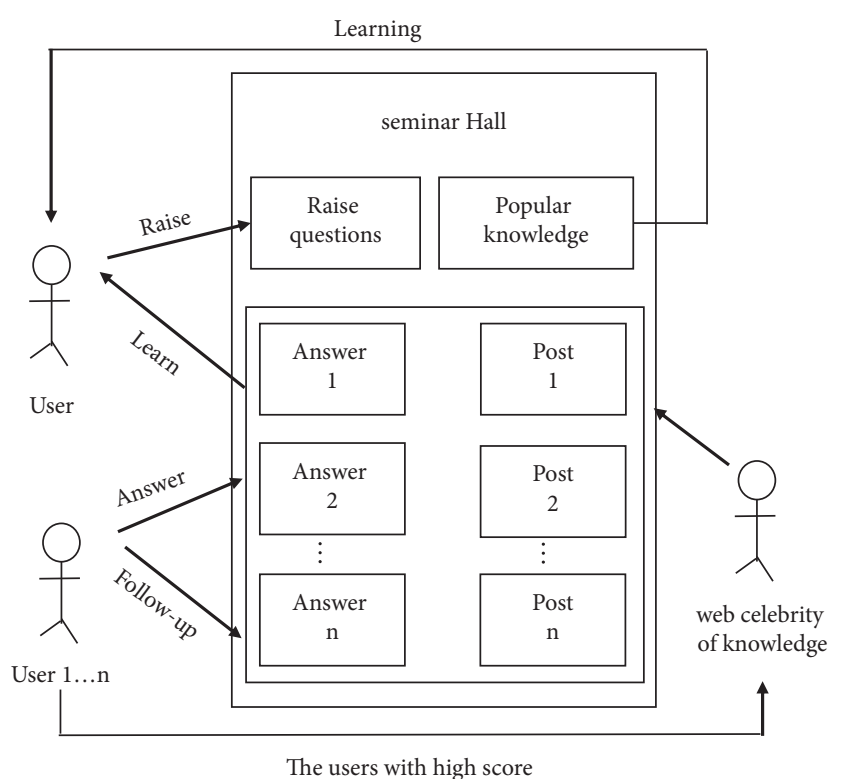

FIGURE 5: Learning process based on seminar hall.

3.3. Learning Portraits. Learning portrait is a visual description of the occurrence and development of learning, including content, activities, and effects. It can record and visualize the information of user's learning content, activities, and effect with the help of computer graphics, statistics, and other technologies and encourage users to learn independently.

(i) Learning content describes "what to learn." Its presentation forms include the name, professional fields, and multimedia attributes of knowledge points, such as text, audio, video, animation, and so on.

(ii) Learning activities describe "how to learn," which include learning activities and training. Learning activities are oriented by a knowledge map, and the elements presented include the learning time and discontinuity of knowledge points and those operations related to learning objectives.

(iii) Learning training directly affects the learning content, which is a concrete manifestation of the understanding of learning content. Its presentation factors include training duration and completion.

(iv) Learning effect describes "progress of learning," which refers to the result after completing a learning activity. The learning effect can be customized by a "self-definition indicator" to replace the traditional measurement. The "self-definition indicator" can reflect the real learning effect and level of learners. The elements presented can be learning time, training, etc.

\section{Conclusion}

This research applies a model framework of aerospace post capacity. For the characteristics of aerospace posts, the post competency model framework is explained. Different ability levels, from low to high, are designed to represent professional knowledge, professional skill, and professional capability. The framework of learning activity is designed to achieve specific learning objectives under the guidance of certain teaching ideologies and study theory. The intelligent on-the-job learning model includes four elements: (i) learning platform, (ii) learning resources, (iii) learning methods, and (iv) learning evaluation.

The learning method based on the knowledge map is explained. The learning process based on a knowledge map includes the following five steps: (i) building a post ability model, (ii) forming a knowledge map, (iii) selecting knowledge points for learning, (iv) training, and (v) learning portrait.

Also, the learning style based on the seminar hall is discussed which will help in knowledge sharing among the users. Users can fully discuss, share knowledge, and exchange information in the seminar hall, and those with more contribution of knowledge, ideology, and activity can become web celebrities of knowledge.

\section{Future Work}

In the future, we aim to work on project-based learning. PBL is a teaching method in which students learn by actively engaging in real-world and personally meaningful projects. It is more closely associated with 21 st century learning skills than perhaps any other form of learning and new technology. PBL allows students to reflect upon their ideas and opinions and make decisions that affect project outcomes and the learning process in general. The final product results in high-quality, authentic products and presentations.

\section{Data Availability}

The data used to support the findings of this study are included within the article.

\section{Conflicts of Interest}

The authors declare that they have no conflicts of interest.

\section{References}

[1] Q. Jiang and G. Xu, "Project-based curriculum research of vocational education based on the task," Vocational and Technical Education, vol. 26, pp. 46-50, 2005.

[2] N. Ostashewski, M. Cleveland-Innes, and N. Parker, "Learning to learn online: experiences of novice learners in a high-quality MOOC," in Proceedings of the Circles of Conversation, Canadian Society for the Study of higher Education, Columbia Vancouver, Canada, 2016.

[3] K. J. Wang, D. A. Rizqi, and H. P. Nguyen, "Skill transfer support model based on deep learning," Journal of Intelligent Manufacturing, vol. 32, 2021.

[4] N. Y. Zhang and N. L. Li, "Process configuration model-an an approach to intelligent agent-based software framework," in Proceedings of the Conference on Machine Learning \& Cybernetics IEEE Computer Society, Xi'an, China, 2003.

[5] L. Chiapello, "Professional knowledge," McGill Journal of Education, vol. 47, no. 1, p. 37, 2012. 
[6] T. Wragg, Professional Knowledge, Professional Lives: Studies in Education and Change, Open University Press, London, UK, 2003.

[7] Z. Qi, "Strengthen professional quality training to develop competitive calisthenics," Journal of Anhui Sports Science, vol. 23, pp. 23-24, 2002.

[8] E. Kurilovas, I. Zilinskiene, and V. Dagiene, "Recommending suitable learning paths according to learners' preferences: experimental research results," Computers in Human Behavior, vol. 51, pp. 945-951, 2015.

[9] S. Ma and M. Tang, "Training innovation based on learning map in state grid Jiangsu electric power university," The Technology of HRD, vol. 2, pp. 20-46, 2014, in Chinese.

[10] C. Qu, J. Fang, and X. Mei, "Training curriculum development based on post competency model," The Technology of HRD, vol. 8 , pp. 32-36, 2010, in Chinese. 